\title{
The acquisition of answers to yes - no questions in European Portuguese: syntactic, discourse and pragmatic factors
}

\author{
ANA LÚCIA SANTOS
}

\begin{abstract}
This paper (i) describes the patterns of answers to yes-no questions in European Portuguese; (ii) presents data illustrating the acquisition of these patterns; (iii) argues that the acquisition of patterns of answer to yes-no questions in European Portuguese provides evidence for two types of modularity in the acquisition process: modularity of syntax, discourse and pragmatics and modularity within the computational system.
\end{abstract}

\section{Types of answer to yes-no questions in European Portuguese}

European Portuguese has different ways of presenting a minimal answer to a yes-no question. I will define a minimal answer as an answer using a minimum of words, more specifically a single word. Example (1) below presents the four (main) ${ }^{1}$ ways to provide a minimal answer to a yes-no question: SIM (yes) answers, SER (BE) answers, verbal answers and adverbial answers. The next sections deal with restrictions on the occurrence of each type of answer.

(1) Q: Ele já encontrou a chave? he already found $\left[3^{\text {rd }} \mathrm{sg}\right]$ the key

'Has he already found the key?'
A: a. Sim.-
SIM (yes) answer
yes

\footnotetext{
${ }^{1}$ Other types of answer could be referred to: "O.K." answers, "Tá" answers, for instance. "Tá" answers will be referred to in section 3.2.2.; other types are not referred here.
} 
b. Encontrou. - verbal answer found $\left[3^{\text {rd }} \mathrm{sg}\right]$

c. É. / Foi. - SER (BE) answer is / was

d. Já. - adverbial answer already

\section{Arguments for the different status of the different types of answer}

This section provides a distinction of the four types of answer presented. It will be shown that none of the four types of answer are exactly equivalent, since they yield syntactic, discourse or pragmatic differences.

\subsection{SIM (yes) answers and SER (BE) answers are not equivalent to verbal} answers

The first argument supporting the claim that SIM (yes) answers and SER (BE) answers must be distinguished from verbal answers comes from typical cases of identificational focus ("only" structures or clefts - cf. Kiss, 1998) combined with question - answer contexts. In these cases, a focalization operator in pre-verbal position precludes verbal answers, whereas SIM (yes) or SER (BE) answers remain available.

$$
\begin{aligned}
& \text { (2) Q: O João só estudou Geografia? } \\
& \text { The João only studied }\left[3^{\text {rd }} \mathrm{sg}\right] \text { Geography } \\
& \text { 'Did João only study Geography?' } \\
& \text { A: Sim. / Foi. / É. / Só. / *Estudou. } \\
& \text { yes / was / is / only / studied }\left[3^{\text {rd }} \mathrm{sg}\right] \\
& \text { (3) Q: Foi no cinema que a Maria desmaiou? } \\
& \text { Was in+the cinema that the Maria fainted[ } \left.3^{\text {rd }} \mathrm{sg}\right] \\
& \text { 'Was it in the cinema that Maria fainted?' } \\
& \text { A: Sim. / Foi. /É. / *Desmaiou. } \\
& \text { yes /was / is / fainted[ } \left.3^{\text {rd }} \mathrm{sg}\right]
\end{aligned}
$$

From the examples above, it is also clear that the unavailability of the verbal answer is independent from what is focalized: in (2), focalization affects either the VP or the internal argument; in (3), a VP adjunct is focalized. Example (4), where a subject is clefted, also supports this claim:
(4) Q: Foi a
Maria que
desmaiou
no cinema? 'Was it Maria who fainted in the cinema?' 


$$
\begin{array}{lll}
\text { A: Sim. /Foi. / É. / } & \text { *Desmaiou. } \\
\text { yes / } / \text { was / is / } & \text { fainted }\left[3^{\text {rd }} \mathrm{sg}\right]
\end{array}
$$

The second fact that distinguishes SIM (yes) or SER (BE) answers from verbal answers comes from different contexts, namely confirmative contexts.

First, it must be shown that confirmations pattern like answers to yes - no questions to the extent they allow both SIM (yes), SER (BE) confirmations and verbal or adverbial confirmations:

(5) Speaker A: O João já toma três refeições por dia. the João already takes three meals per day 'João is already taking three meals per day.'

Speaker B: Sim. / É. / Já. / Toma.

yes is already takes

The same effects shown by identificational focus structures in question / answer pairs (cf. 2) are available in confirmations:

(6) Speaker A: O João só toma três refeições por dia. the João only takes three meals per day 'João only takes three meals per day.'

Speaker B: Sim. / É. / Só. / *Toma.

yes is only takes

Therefore it is interesting to notice that confirmative contexts present independent evidence in support of the distinction between SIM (yes) or SER (BE) confirmations and verbal confirmations. Consider the following discourse context:

(7) Speaker A: Eles são gordos porquê?

they are fat why

'Why are they fat?'

Speaker B: Comem bananas. eat $\left[3^{\text {rd }} \mathrm{pl}\right]$ bananas

'They eat bananas.'

Speaker C: Comem. / É. / Sim.

eat $\quad /$ is / yes

Crucially, the meaning of the verbal confirmation in (7) is different from the meaning of the SIM (yes) or SER (BE) confirmations: the verbal confirmation is interpreted as "Yes, they eat bananas."; SIM (yes) and SER (BE) confirmations are interpreted as "Yes, they are fat because they eat bananas.". This means that SIM (yes) or SER (BE) confirmations are able to recover the answer status of the confirmed sentence, unlike verbal confirmations. 
If (i) one makes a classic assumption about scope, i.e., scope relations are defined under c-command and (ii) one assumes that the material recovered in an answer is the material in the scope of the only lexically realized item in the answer, the difference between verbal answers on one hand and SIM (yes) and SER (BE) answers on the other should correspond to a syntactic difference, a scope difference: "sim" (yes) and SER (BE) must occupy a position structurally higher than the position occupied by the verb in a verbal answer in order to recover higher material. Such an analysis also assumes that, in order to answer to a yes-no question, one must identify the material focused in the question (what is being asked) and recover this material in the answer. The facts presented in this section may be explained under the assumption that the material focused in yes-no questions includes the verb and everything it c-commands in the default cases. In these cases, a verbal answer is able to recover the material focused in the question. The interpretation happens by default in the absence of syntactic (or other) factors capable of changing the definition of the material focused in the question. When syntactic (identificational focus, for instance) or discourse factors intervene, the material focused in the question may be defined by higher categories - in these cases, a verbal answer is unavailable.

This data is in agreement with the proposal in Santos (2002a) and (2002b). Santos (2002b) claims that verbal answers should be analyzed as instances of VP ellipsis (following Martins, 1994). However, Santos departs away from Martins (1994) with respect to the position the verb occupies in minimal answers. As this data and the data presented in Santos (2002a) and (2002b) show, it is not possible to claim that the verb occupies a high left peripheral position ( $\Sigma$ in Martins, 1994) in minimal answers (and in sentences in general in European Portuguese). Santos (2002b) retains from Martins (1994) that minimal verbal answers are instances of VP ellipsis, under the assumption that the verb is in T in VP ellipsis (according to Matos, 1992 and Cyrino \& Matos, 2002 and to the general idea of short verb movement in Portuguese as in Costa, 1996). As for "sim" (yes) and SER (BE) in minimal answers, there is nothing that prevents them from occupying a high left peripheral position, for instance $\Sigma$. Moreover, according to this analysis, the interpretation of a yes-no question using the default strategy allows the identification of $\mathrm{T}$ and all it c-commands as the material focused in the question.

\subsection{SIM (yes) and SER (BE) are not exactly equivalent answers}

Until now, SIM (yes) and SER (BE) answers were shown to be syntactically equivalent. The aim of this section is to show they are not equivalent in 
all contexts: their difference will be established in pragmatic and discourse terms. $^{2}$

Although SIM (yes) and SER (BE) answers are equivalent in most contexts, there are differences between the two types of answer when contexts with certain pragmatic contrasts are taken into account.

Consider the following question-answer pair:

(8) Q:

$\begin{array}{llll}\text { Podes } & \text { fechar } & \text { a } & \text { janela? } \\ \text { could }\left[2^{\text {nd }} \mathrm{sg}\right] & \text { close } & \text { the window }\end{array}$

A: $\quad$ Sim. / \#É. / Posso. 'Would you close the window?' yes / is / can[ $\left.1^{\text {st }} \mathrm{sg}\right]$

(9) Q: Vamos tomar café? go[ $\left.1^{\text {st }} \mathrm{pl}\right]$ take coffee 'Shall we have coffee?'

A: $\quad$ Sim. / \#É. / Vamos. yes / is / go[ $\left.1^{\mathrm{st}} \mathrm{pl}\right]$

Even though the questions in (8) and (9) have the syntactic structure of yes-no questions, they differ from all the data presented sofar with respect to their pragmatics. These questions are normally interpreted as indirect speech acts (Searle, 1975): in (8) the speaker must be asking someone to close the window (and not asking about the physical possibility of closing that window - in Portuguese the same modal verb would be used in both situations); the question in (9) is normally understood as an invitation and not as an information request. The unavailability of the SER (BE) answer must be related to these facts.

Notice that it is possible to improve the status of SER (BE) answers in these question-answer pairs by creating an adequate situational context: consider (9) and suppose that somebody takes a person to an unknown place; then that person asks the question in (9) in order to obtain information about where they are going. In this situational context, European Portuguese speakers would perfectly accept "É." as an answer to that question (SIM - yes and verbal answers remain acceptable in that case).

This difference between SIM (yes) answers and SER (BE) answers must be defined as a difference following from a pragmatic constraint on the use of SER (BE) answers: the latter type of answers is not available as agreeing answers, whereas SIM (and verbal) answers may be used as agreeing answers in those contexts.

\footnotetext{
${ }^{2}$ I assume that pragmatics accounts for the relation between language and the situational context and discourse for the relation between language and the discourse context. The fact that both domains can be subsumed under pragmatics is not relevant for this work.
} 
The second difference between SER and SIM (yes) or verbal answers is related to discourse contexts and is slightly more difficult to define: SER answers seem to be especially adequate in confirmative contexts.

Consider the following discourse contexts:

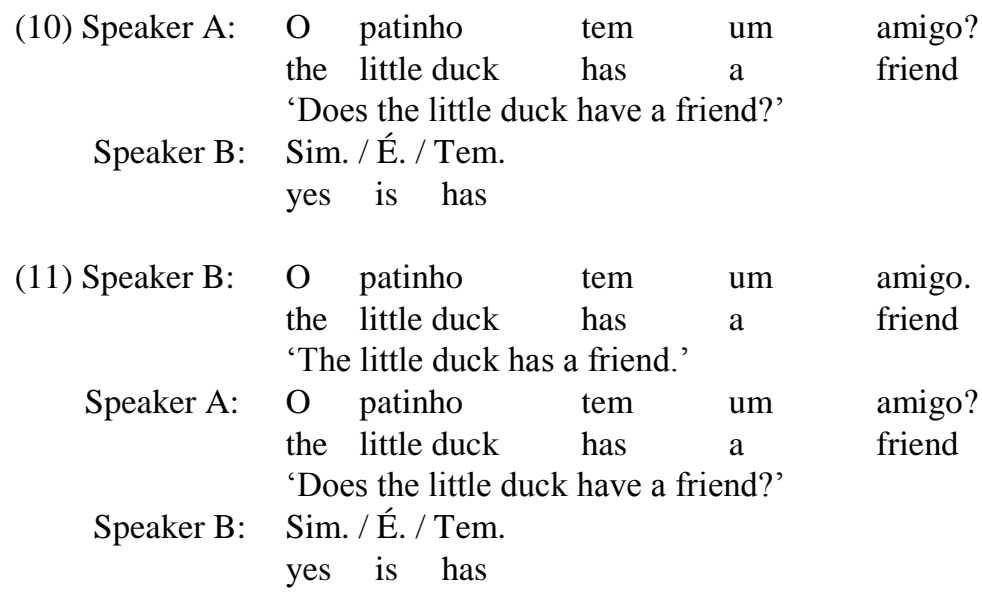

Although the SER (BE) answer is accepted in (10), some European Portuguese speakers do not consider it the most natural answer in that context. Crucially, the same speakers consider a SER (BE) answer natural in a context like (11) - I would like to show that this happens for discourse reasons. In fact, the discourse context in (11) forces the yes-no question to be interpreted as a request for confirmation and this must be the reason why SER (BE) answers occur more easily in these contexts - the first intuition native speakers have about SER (BE) answers is in fact that they are normally felt as confirmations.

However, let us proceed and check what is confirmed in (11). The question by Speaker A in (11) may in fact receive two interpretations as requests for confirmation - the availability of the verbal answer depends on the assumed interpretation.

- interpretation 1: Speaker A thinks it is strange that the little duck has a friend and asks the question to confirm the fact that the little duck has a friend (is it true about $x$, $x$ being the little duck, that $x$ has a friend?);

- interpretation 2: Speaker A is not sure about what has been said by speaker B and asks the question to confirm what was said (is it true about $x$, $x$ being what you said, that $x=$ the little duck has a friend?).

Both interpretations take the question as a confirmation request, both are allowed in the discourse context and in both cases a SER (BE) answer and a SIM (yes) answer are possible. The difference between both interpretations 
hinges on syntactic factors: it is clear that interpretation 1 corresponds to a situation where the material focused in the question, defined by default as the category hosting the verb and everything it c-commands has not been changed. Under interpretation 2, higher material must be focused in the question - the discourse context itself allows an interpretation of the question distinct from the default one. Crucially, SIM (yes) and SER (BE) answers are possible in both contexts but a verbal answer is only possible where interpretation 1 is assumed.

This reinforces the conclusion of the last section, which points to a syntactic difference between verbal answers, on the one hand, and SIM (yes) and SER (BE) answers, on the other. It must also mean that SIM and SER are syntactically equivalent although they exhibit different discourse and pragmatic interpretations: on the one hand, SER answers may not be interpreted as agreement and, consequently, may not be an agreement answer to syntactic yes-no questions with the pragmatic value of invitations or requests in general; on the other hand, SER answers seem to have specialized as confirmations and are a more natural type of answer when the discourse context allows the yes-no question to be interpreted as a confirmation.

\subsection{Adverbial answers are not equivalent to verbal answers or to SIM (yes)} or to SER (BE) answers

Adverbial minimal answers obtain in contexts where the yes-no question presents a certain type of adverb, typically in preverbal position - the following adverbs produce those effects: "só" (only), "apenas" (only), "talvez" (maybe), "quase" (almost), "já" (already), "também" (also), "até" (even), "ainda" (still), "sempre" (always) ${ }^{3}$. These adverbs do not form an homogeneous class (cf. Santos, 2002a). Therefore, adverbial answers do not form a homogeneous type of answer (cf. 2.4).

\footnotetext{
${ }^{3}$ Gonzaga (1997) and Brito (2001) discuss the different values of the adverb "sempre" in European Portuguese by contrasting the temporal "sempre" ("always") with a non-temporal "sempre". Gonzaga (1997) (but not Brito, 2001) claims that the non-temporal adverb, which is obligatorily preverbal, has a confirmative meaning (i), taken from Gonzaga (1997: 160), would be a case where "sempre" occurs with a non-temporal meaning. Moreover, Gonzaga (1997) claims that confirmative "sempre" occupies $\Sigma$. I will not retain this proposal here. Notice that non-temporal "sempre" is odd as an answer to a yes-no question: this is unexpected if one assumes non temporal "sempre" occurs in the same projection as "sim" ("yes").

(i) $\mathrm{O}$ João sempre está em casa.

the João indeed is at home

João is at home, indeed.

(ii) Q: O João sempre está em casa?

the João indeed is at home

João is at home indeed?

P: Sim. / ??Sempre.

yes indeed
} 


\subsubsection{Adverbial answers are not equivalent to verbal answers}

Example (2), repeated here as (12), shows that (at least some) adverbial answers are syntactically different from verbal answers: in a context where an adverbial answer is possible, a verbal answer may be impossible (cf. section 2.4. for further information) ${ }^{4}$.

$$
\begin{array}{rlll}
\text { (12) Q: } & \text { O João } \quad \text { só } & \text { estudou } & \text { Geografia? } \\
\text { The João } & \text { only } & \text { studied[ } \left.3^{\text {rd }} \mathrm{sg}\right] & \text { Geography } \\
\text { 'Did João only study Geography?' } & \\
\text { A: } & \text { Sim. / Foi. / É. / Só. / *Estudou. } \\
& \text { yes / was / is / } & \text { only / studied[ } \left.3^{\text {rd }} \mathrm{sg}\right]
\end{array}
$$

If one maintains the idea that a minimal answer to a yes-no question must recover the material focused in the question and one assumes that the material recovered in an answer is the material in the scope of the only lexically realized item in the answer, this must mean the following:

(i) the material focused in the question in (12) is larger than the scope domain defined by the verb and all it c-commands;

(ii) the adverbial answer in (12) recovers more material than the verbal answer and this must happen because the adverb c-commands the verb.

\subsubsection{Adverbial answers are not equivalent to SIM (yes) or SER (BE) answers}

There is evidence to say that adverbial answers have narrower scope than SIM (yes) or SER (BE) answers.

An argument in support of this claim comes from confirmations in enlarged discourse contexts. Take a context of a confirmation as in (13), similar to the confirmation context analyzed in 2.1.:

$\begin{array}{rlll}\text { (13) Speaker A: } & \begin{array}{l}\text { Eles são } \\ \text { they are }\end{array} & \begin{array}{l}\text { gordos fat } \\ \text { 'Why are they fat?' }\end{array} & \begin{array}{l}\text { porquê? } \\ \text { why }\end{array} \\ \text { Speaker B: } & \begin{array}{l}\text { Só } \\ \text { only comem eat }\left[3^{\text {rd }} \mathrm{pl}\right] \text { bananas. }\end{array} & \\ & \begin{array}{l}\text { 'They only eat bananas.' } \\ \text { Speaker C: }\end{array} & \begin{array}{l}* \text { Comem. / Só. / É. / Sim. } \\ \text { eat / only / is / yes }\end{array}\end{array}$

\footnotetext{
${ }^{4}$ Another argument supporting the distinction between adverbial and verbal answers comes from crosslinguistic evidence. In Spanish, for instance, verbal answers are not allowed, but some adverbial answers are possible; in English, on the contrary, verbal answers are possible, but adverbial answers are not. This is discussed in Santos (2002a) and (2002b).
} 
Let us consider the adverbial confirmation and the SIM (yes) and SER (BE) confirmations (the fact that the verbal answer is excluded in these contexts should receive an explanation similar to the one presented for example 12 in 2.3.1). In this case, it is important to notice that the adverbial confirmation has a distinct interpretation from the SIM (yes) or SER (BE) confirmations: the adverbial confirmation is interpreted as "Yes, they only eat bananas."; the SIM (yes) and SER (BE) confirmations are interpreted as "Yes, they are fat because they only eat bananas.". This means that SIM (yes) or SER (BE) confirmations can recover the answer status of the confirmed sentence, adverbial confirmations cannot.

In section 2.1., it was shown that verbal confirmations could also not recover the answer status of the confirmed sentence. To this extent, adverbial and verbal confirmations pattern alike, showing that the verb and the adverb have narrower scope than SIM or SER in answers; however, adverbial and verbal answers differ in the way discussed in section 2.3.1.

Further evidence is provided by answers to yes-no questions with the value of confirmations. Consider a context similar to the one analyzed in section 2.2 .

$\begin{array}{lllll}\text { (14) Speaker B: } & \begin{array}{l}\text { O patinho só tem um } \\ \text { the little duck only has amigo. } \\ \text { 'The little duck only has a friend.' }\end{array} & \text { friend } \\ \text { Speaker A: } & \begin{array}{l}\text { O patinho só tem um } \\ \text { the little duck only has a onigo? }\end{array} & \text { friend } \\ & \text { 'Does the litlle duck only have a friend?' } & \\ \text { Speaker B: } & \begin{array}{l}\text { Sim. /É. / Só. / *Tem. } \\ \text { Yes is only has }\end{array} & \end{array}$

Now consider the two possible interpretations of the yes-no question and how those interpretations are recovered by the SIM (yes) and SER (BE) answers and the adverbial answer (the verbal answer in this context is excluded for the same reasons it is excluded in 13).

The question by Speaker A in (14) may receive two interpretations, both as confirmation requests - crucially, the adverbial confirmation is only available in the case interpretation 1 is assumed:

- interpretation 1: Speaker A thinks it is strange that the little duck only has a friend and asks the question to confirm the fact that the little duck only has a friend (is it true about $x, x$ being the little duck, that $x$ only has a friend?);

- interpretation 2: Speaker A is not sure about what has been said by speaker B and asks the question to confirm what was said (is it true about $x, x$ being what you said, that $x=$ the little duck only has a friend?). 
In section 2.2., it was shown that verbal answers in similar contexts behave similarly to the adverbial answer in this context: if interpretation 2 is assumed, the adverbial answer is not an adequate type of answer. Once again, adverbial and verbal answers pattern alike, showing that the adverb and the verb have narrower scope than SIM (yes) or SER (BE) in answers; however, as shown in section 2.3.1, a verbal answer still has narrower scope than (some types of) adverbial answers 5 .

\subsection{Adverbial answers are not an homogeneous type of answer}

So far we have seen cases of adverbial answers to yes-no questions where the adverbial answer does not have the same distribution as a verbal answer, i.e., the adverbial answer is possible when the verbal answer is not. This is the case of answers to questions with the adverb "só" (only), a focalization operator, placed in a preverbal position. This is also the case of answers to questions with the adverbs "talvez" (maybe) or "quase" (almost) placed in preverbal position. However, when other adverbs able to occur as an answer are found in preverbal position in a yes-no question, the adverbial answer has the same distribution as a verbal answer: it is possible to answer with the verb to a yes-no question with an adverb of this type.

$$
\begin{aligned}
& \text { (15) Q: O Tomás já bebeu o leite? } \\
& \text { the Tomás already } \operatorname{drank}\left[3^{\text {rd }} \mathrm{sg}\right] \text { the milk } \\
& \text { 'Has Tomás already drunk the milk?' } \\
& \begin{array}{llll}
\text { A: } & \text { Sim. /É. / Já. / Bebeu. } \\
\text { yes is } & \text { already } & \operatorname{drank}\left[3^{\text {rd }} \mathrm{sg}\right]
\end{array}
\end{aligned}
$$

Table I summarizes the possibilities of answering to yes-no questions when the question includes an adverb allowing an adverbial answer in a preverbal position ${ }^{6}$ :

\footnotetext{
${ }^{5}$ In Santos (2002a) and (2002b) I present crosslinguistic evidence for distinguishing adverbial answers and SIM (yes) or SER (BE) answers.

${ }^{6}$ An anonymous reviewer suggested that it would be relevant to establish clear-cut class(es) of adverbs that allow minimal adverbial answers, based upon the properties they share in addition to licensing ellipsis in answers. I agree but I leave this for future research, since it is not crucial to the discussion of the hypotheses I develop here. The same reviewer points out that it is difficult to imagine a question-answer pair where the adverb "até" (even) appears as a minimal adverbial answer. The question-answer pair in (i) is one of these cases:

(i) Q: O professor até ofereceu os apontamentos? the teacher even offered the notes

'The teacher has even offered his notes?'

A: Sim. / Foi. / Até. / Ofereceu.

yes was even offered

Notice however that in case the adverb "até" (even) has focus over the preverbal subject, the verbal answer may be blocked (cf. ii). The fact that "até" (even) may receive an analysis as a focalization operator, in the same fashion as "só" (only),
} 
Table I. Possible answers to yes-no questions with different adverbs in preverbal position.

\begin{tabular}{ll}
\hline Group A & Group B \\
Possible answers: & Possible answers: \\
$\checkmark$ SIM (yes) answer & $\checkmark$ SIM (yes) answer \\
$\checkmark$ SER (BE) answer & $\checkmark$ SER (BE) answer \\
$\checkmark$ adverbial answer & $\checkmark$ adverbial answer \\
* verbal answer & $\checkmark$ verbal answer \\
\hline Só (only) & Já (already) \\
Talvez (maybe) & Também (also) \\
Quase (almost) & Até (even) \\
& Ainda (still) \\
& Sempre (always) \\
\hline
\end{tabular}

If we maintain the idea that the material recovered in an answer must be the material focused in the yes-no question and if we also maintain the idea that this material is identified as the lexically realized item in the answer and all the material it c-commands, the possibility of obtaining a verbal answer in a context as (15) needs to be explained. For the moment, let us simply say that such adverbs do not affect the identification of the material focused in the question in any relevant way.

Notice also that, under the assumption that the material recovered in an answer is in the scope (this means under c-command) of the only lexically realized item in the answer, we obtain an explanation for the following contrasts:

$\begin{array}{llllll}\text { (16) Q: } & \text { O João } & \text { só } & \text { comeu } & \text { a } & \text { sopa? } \\ \text { the } & \text { João } & \text { only } & \text { ate }\left[3^{\text {rd }} \mathrm{sg}\right] & \text { the } & \text { soup }\end{array}$

'Did João only eat the soup?'

A: Sim. /É. / Só. /*Comeu.

yes is only ate[ $\left.3^{\text {rd }} \mathrm{sg}\right]$

may contribute to the (desirable) establishment of adverbial classes and to the definition of their interaction with answer patterns. Clearly, the information on Table I is not complex enough, since it does not distinguish between different pre-verbal positions.

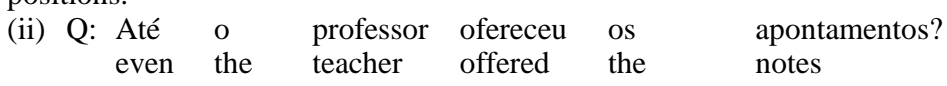
'Even the teacher has offered his notes?'

A: Sim. / Foi. / Até. / ??Ofereceu. yes was even offered 


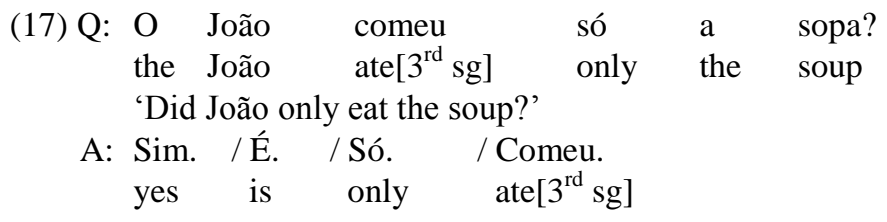

When an adverb of Group A in Table I is placed in a postverbal position ("talvez" almost is difficult in this position), the verbal answer is possible (cf. 17). In fact, in these cases the verbal answer is able to recover all the material in the scope of the yes-no question: it happens that the verbal answer recovers more than the material in the scope of the question, but this is exactly the way SIM (yes) and SER (BE) answers behave in this case ${ }^{7}$.

\section{Summary:}

The different types of answer to yes-no questions in European Portuguese do not have the same distribution, which means they are not equivalent.

On the one hand, minimal answers to yes-no questions differ syntactically. This syntactic difference has consequences as to the amount of material each type of answer may recover: SIM (yes) and SER (BE) answers recover more material than adverbial answers; adverbial answers with adverbs such as "só" (only), "talvez" (maybe) and "quase" (almost) may recover more material than verbal answers. If these differences are understood as scope differences, and if we define scope as c-command, it must be assumed that SIM (yes) and SER (BE) occupy higher clausal positions than adverbs and verbs in minimal answers. According to the same criteria, adverbs in minimal answers (at least those belonging to group A of Table I) occupy a higher clausal position than verbs in the same context, in the cases these adverbs are in preverbal position. I have assumed that SIM (yes) or SER (BE) in minimal answers must occupy a left peripheral position in the clause, which can be identified as $\Sigma$, in terms of Laka (1990) or Martins (1994). Verbs in verbal answers were assumed to occupy the head of $\mathrm{T}(\mathrm{ense})$.

\footnotetext{
${ }^{7}$ An anonymous reviewer suggested that the possibility of obtaining an adverbial answer in cases where the adverb "só" is post-verbal requires a clarification of the relation between the structure of the question and the structure of the related answer. If, as the reviewer claims, one indeed accepts that confirmative elements always occur in $\Sigma$, the conclusion should be that elliptical answers may have some structural autonomy with respect to their non-elliptical antecedents: "só" in the answer should appear in $\Sigma$ but it is impossible to say that the postverbal adverb occupies this position when it occurs in the question. Although this is an interesting point, I do not take for granted that all confirmative elements occur in $\Sigma$ : in section 2.1, I claimed that the verb in verbal minimal answers occupies T, whereas SIM (yes) or SER (BE) occupy $\Sigma$. Hence, in the case of the postverbal adverb "só" (only), it is possible that it appears in the answer stacked in the same structural position it occupies in the question. This problem certainly deserves future investigation.
} 
On the other hand, different patterns of minimal answers to yes-no questions do not only differ in a syntactic way. SIM (yes) and SER (BE) answers do also differ with respect to interpretation. This difference is pragmatically or discursively determined.

\section{Data from the acquisition of European Portuguese}

In this section, I will present data of spontaneous production of two monolingual children acquiring European Portuguese: Inês (1;6.6 - MLUw 1.50 to 3;11.12 - MLUw 3.84) and Tomás (1;6.18 - MLUw 1.29 to $1 ; 10.8$ - MLUw 1.68). The children were videotaped, Inês on a monthly basis and Tomás every two weeks. The data was treated using CHILDES (MacWhinney \& Snow, 1985). ${ }^{8}$

Given the conclusions in section 2, the evaluation of the data seeks to find an answer for the following questions:

1. Do the syntactic differences between the different types of minimal answer have consequences for the process of acquisition?

2. Do the pragmatic and discourse differences between SIM (yes) and SER (BE) answers reflect in the acquisition process?

3. How do the answers to the preceding questions contribute to our further knowledge about the process of language acquisition?

3.1. Stages in the acquisition of minimal answers and emergence of functional categories

In this section, I will show that not all types of minimal answers are available at the beginning of the acquisition process. The following table presents the occurrence of the different types of minimal answers in Inês' files organized in stages'

\footnotetext{
${ }^{8}$ Inês was videotaped by Maria João Freitas as part of the work developed for her Ph.D. Dissertartion (cf. Freitas, 1997) and as part of the project PCSH/C/LIN/524/93 developed at Laboratório de Psicolinguística da Faculdade de Letras da Universidade de Lisboa. The first sessions of Inês were partially transcribed by Maria João Freitas and completed by myself, other sessions were transcribed by Teresa Costa and myself. Tomás was videotaped and transcribed by myself. Each of the sessions correspond to approximately 40 / 45 minutes of videotaping. The treatment of Inês and Tomás' data using CHILDES is of my responsibility.

9 The number of each type of answer per session is not presented here for space reasons. However, it is important to know how many sessions are put together into each of the stages: Stage I refers to the sessions corresponding to $1 ; 6.6,1 ; 7.2$ and 18.2; Stage II includes sessions $1 ; 9.19,1 ; 10.29$ and $2 ; 1.10$; Stage III includes the sessions corresponding to $2 ; 2.1,2 ; 3.8,2 ; 4.19,2 ; 5.24,2 ; 7.16,2 ; 8.23,2 ; 10.20$, $2 ; 11.21,3 ; 0.15,3 ; 2.2,3 ; 4.6,3 ; 5.28,3 ; 7.29,3 ; 10.1,3 ; 11.12$. Also notice that this table puts together answers to tags and answers to non-tag yes-no questions since there were no significant differences in the two types of answer with respect to what concerns us at this point.
} 
Table II. Stages in the acquisition of minimal answers in Inês' data.

\begin{tabular}{lccc} 
STAGE & I & II & III \\
Age & $1 ; 6.6-1 ; 8.2$ & $1 ; 9.19-2 ; 1.10$ & $2 ; 2.1-3 ; 11.12$ \\
\hline
\end{tabular}

\begin{tabular}{lclcccc} 
Minimal answer Type & $\mathrm{N}$ & $\%$ & $\mathrm{~N}$ & $\%$ & $\mathrm{~N}$ & $\%$ \\
Verbal & 12 & $\mathbf{1 0 0}$ & 71 & $\mathbf{8 5 . 5}$ & 138 & $\mathbf{5 9 . 4}$ \\
SIM (yes) & 0 & 0 & 3 & $\mathbf{3 . 6}$ & 79 & $\mathbf{3 4}$ \\
SER (BE) & 0 & 0 & 7 & $\mathbf{8 . 4}$ & 6 & $\mathbf{2 . 5}$ \\
Adverbial & 0 & 0 & 2 & $\mathbf{2 . 4}$ & 9 & $\mathbf{3 . 8}$ \\
\hline Total & 12 & & 83 & & 232 &
\end{tabular}

Table II shows it is possible to identify three stages in the acquisition of minimal answers in Inês' data: a first stage where the verbal answer is the only type of answer available, a second stage where other types of minimal answers emerge and a third stage where the use of SIM answers increases.

If we now recover the idea (developed in section 2) that verbal answers are syntactically different from SIM (yes) or SER (BE) answers since the verb in verbal minimal answers occupies a position lower (namely, T) than SIM (yes) or SER (BE) occupy in minimal answers (I have assumed they occupy $\Sigma$ ), these data seem to show that minimal answers involving lower categories are earlier than minimal answers involving higher categories. ${ }^{10}$

It is also worth to notice that SER (BE) answers emerge at the same time as SIM (yes) answers but they reach their higher frequency at an intermediate stage (Stage II in Table II). At this stage, SER (BE) answers are more frequent than SIM (yes) answers, a situation that will be inverted in the next stage. This may be the clue to evaluate Tomás' data (cf. Table III ${ }^{11}$ ). At this moment of the acquisition process, Tomás seems to be at a stage similar to the intermediate stage (stage II) identified in Inês' data: he produces answers that are different from verbal answers but he has not yet generalized the production of SIM (yes) answers. Significantly, SER (BE) answers are more frequent than SIM (yes) answers at this stage, which is exactly what happened at the intermediate stage in Inês' files. As will be shown in the next section, the child in this stage produces more SER (BE) answers than an adult would produce, at

10 The higher proportions of verbal answers in the early stages is not due to an absence of discourse contexts where a SIM (yes) answer would be possible: as shown in section 2, SIM (yes) answers are possible for any yes-no question (the same does not apply to verbal answers).

11 Once again the exact number of each type of answer per session is not presented here for space reasons. However it is important to know that this stage in Tomás' data refers to the following sessions: $1 ; 6.18,1 ; 7.14,1 ; 8.16,1 ; 9.14$ and $1 ; 10.8$. As in Table II, this table puts together answers to tags and answers to non-tag yes-no questions since there were no significant differences in the two types of answer with respect to what concerns us at this point. 
least in the sense he produces SER (BE) answers in contexts where they would not be possible for an adult. ${ }^{12}$

Table III. Frequency of minimal answers in Tomás’ data.

\begin{tabular}{lrr} 
& Age & \multicolumn{2}{c}{$1 ; 6.18$} & $-1 ; 10.8$ \\
\cline { 2 - 3 } Minimal answer Type & $\mathrm{N}$ & $\%$ \\
Verbal & 86 & 71.07 \\
SIM (yes) & 4 & 3.30 \\
SER (BE) & 29 & 23.96 \\
Adverbial & 2 & 1.65 \\
\hline Total & 121 &
\end{tabular}

In strict syntactic terms and recovering what has been said about Inês' data, at this point Tomás seems to have acquired the functional category occupied by SIM (yes) and SER (BE) in minimal answers. For the reasons presented in section 2, this must be a high category, at least as high as necessary to recover all the material in a sentence and also the answer status of a proposition, for instance. In this sense, the transition between stage I and stage II would mean that a functional category, namely $\Sigma$, has been acquired. Early verbal answers may be taken as evidence for the early availability of $\mathrm{T}$.

There is however another possibility of explaining the transition between stage I and stage II: if verbal answers are the type of answer that is adequate when the material focused in a question is defined by default (cf. section 2), stage I would be a stage where the child is unable to process syntactic (or other) factors forcing an interpretation of the question which deviates from the default one. So the problem could be the ability to assign an interpretation other than the default one to a yes-no question. This problem will be discussed in section 3.3, where I will show that this is not the best explanation: in Stage II, when they are able to produce SIM (yes) or SER (BE) answers, children do not completely master non-default interpretations of yes-no questions.

Summary:

In this section, it was shown that syntactic differences between the different types of minimal answer are reflected in the process of acquisition to the extent that not all types of answer are available from the beginning of the process: minimal answers involving lower categories are acquired earlier than minimal answers involving higher categories. This may be seen as a consequence of the (un)availability of functional categories at the onset of the process.

12 The relative frequency of the different types of minimal answers in these children should be compared to relative frequencies in adult speech - I leave this issue for future research. 


\subsection{Acquisition of syntactic, discourse and pragmatic knowledge}

So far, discourse and pragmatic factors that intervene in minimal answers (cf. section 2) have not been taken into account for the evaluation of Inês' and Tomás' data. The aim of this section is to understand how these children deal with this type of information. I will come to a distinction between the processes of acquiring syntactic, discourse and pragmatic knowledge.

\subsubsection{Syntactic and discourse knowledge}

In section 2, it was shown that SER answers are especially adequate in confirmation contexts, although they are possible in other contexts. One of the ways to evaluate the child's sensitiveness to the specificity of confirmation contexts would be to find out whether SER (BE) answers are more frequent in confirmation contexts than in other contexts. To do this, two types of confirmations will be taken into account: confirmations of preceding declarative sentences (cf. 18) and answers to yes-no questions that are in fact requests for confirmation (cf. 19). The context in (19) is especially interesting to evaluate child's awareness of the specific discourse value of this type of question: in order to understand a question as in (19) as a request for confirmation, the child has to rely either on discourse or intonation, since this type of yes-no question differs intonationally from "true" yes-no questions ${ }^{13}$.

$$
\begin{array}{llll}
\text { (18) Speaker A: O João vai ao } & \begin{array}{l}
\text { cinema. } \\
\text { cinema }
\end{array} \\
\text { the João goes to+the } & \text { 'João goes to the cinema.' }
\end{array}
$$

Speaker B: Sim. É. Vai.

yes / is / goes

(19) Speaker B: O João vai ao cinema. the João goes to+the cinema

'João goes to the cinema.'

Speaker A: O João vai ao cinema?
the João goes to+the cinema
'Does João go to the cinema?'

Speaker B: Sim. É. Vai. yes / is / goes

Tables IV and V present the number of occurrences of SER (BE) answers vs. other types of answer in both types of confirmation contexts and the num-

13 See Mata (1990) for a prosodic analysis of questions with different discourse values in European Portuguese. 
ber of occurrences of SER (BE) answers to true yes-no questions, in Inês' and in Tomás' data. ${ }^{14}$

Table IV. Occurrences of SER (BE) answers in confirmation and other contexts in Inês' data.

\begin{tabular}{|c|c|c|c|}
\hline & $\begin{array}{l}\text { SER (BE) confirma- } \\
\text { tions of preceding } \\
\text { declarative senten- } \\
\text { ces / confirmations } \\
\text { using other types of } \\
\text { answer }\end{array}$ & $\begin{array}{l}\text { SER (BE) answers to } \\
\text { yes-no questions that } \\
\text { are confirmation } \\
\text { requests / other types } \\
\text { of answer to the same } \\
\text { type of questions }\end{array}$ & $\begin{array}{l}\text { SER (BE) answers to } \\
\text { yes-no questions } \\
\text { that are information } \\
\text { requests / other } \\
\text { types of answer }\end{array}$ \\
\hline $1 ; 6.6$ & $0 / 0$ & $0 / 0$ & $0 / 1$ \\
\hline $1 ; 7.2$ & $0 / 0$ & $0 / 0$ & $0 / 1$ \\
\hline $1 ; 8.2$ & $0 / 0$ & $0 / 0$ & $0 / 5$ \\
\hline $1 ; 9.19$ & $0 / 0$ & $0 / 3$ & $2 / 8$ \\
\hline $1 ; 10.29$ & $0 / 0$ & $1 / 2$ & $1 / 15$ \\
\hline $2 ; 1.10$ & $0 / 0$ & $0 / 2$ & $0 / 17$ \\
\hline $2 ; 2.1$ & $1 / 5$ & $0 / 10$ & $0 / 18$ \\
\hline $2 ; 3.8$ & $0 / 1$ & $0 / 3$ & $0 / 5$ \\
\hline $2 ; 4.19$ & $0 / 1$ & $0 / 6$ & $0 / 20$ \\
\hline $2 ; 5.24$ & $0 / 3$ & $0 / 1$ & $0 / 15$ \\
\hline $2 ; 7.16$ & $0 / 1$ & $1 / 5$ & $0 / 18$ \\
\hline $2 ; 8.23$ & $0 / 0$ & $0 / 2$ & $0 / 1$ \\
\hline $2 ; 10.20$ & $0 / 0$ & $0 / 3$ & $0 / 2$ \\
\hline $2 ; 11.21$ & $0 / 3$ & $0 / 2$ & $0 / 8$ \\
\hline $3 ; 0.15$ & $0 / 4$ & $0 / 0$ & $1 / 0$ \\
\hline $3 ; 2.2$ & $0 / 1$ & $0 / 0$ & $0 / 3$ \\
\hline $3 ; 4.6$ & $0 / 3$ & $0 / 0$ & $0 / 3$ \\
\hline $3 ; 5.28$ & $2 / 2$ & $0 / 0$ & $1 / 1$ \\
\hline $3 ; 7.29$ & $0 / 3$ & $0 / 5$ & $0 / 7$ \\
\hline $3 ; 10.1$ & $1 / 1$ & $0 / 0$ & $0 / 5$ \\
\hline $3 ; 11.12$ & $0 / 1$ & $0 / 2$ & $0 / 3$ \\
\hline $\begin{array}{l}\text { Frequency } \\
\text { of SER } \\
\text { (BE) } \\
\text { answers }\end{array}$ & $12,12 \%$ & $4,16 \%$ & $3,24 \%$ \\
\hline
\end{tabular}

${ }^{14}$ Notice that the number of SER (BE) answers to yes-no questions in Table II and III in the preceding section includes both answers to yes - no questions that behave as requests for confirmation and answers to "normal" yes-no questions. 
Table V. Occurrences of SER (BE) answers in confirmation and other contexts in Tomás' data.

\begin{tabular}{l|l|l|l}
\hline & $\begin{array}{l}\text { SER (BE) confirma- } \\
\text { tions of preceding } \\
\text { declarative senten- } \\
\text { ces / confirmations } \\
\text { using other types of } \\
\text { answer }\end{array}$ & $\begin{array}{l}\text { SER (BE) answers to } \\
\text { yes-no questions that confirmation } \\
\text { are } \\
\text { requests / other types } \\
\text { of answer }\end{array}$ & $\begin{array}{l}\text { SER (BE) answers to } \\
\text { yes-no questions } \\
\text { that are information } \\
\text { requests / other } \\
\text { types of answer }\end{array}$ \\
\hline $1 ; 6.18$ & $1 / 0$ & $1 / 0$ & $1 / 4$ \\
$1 ; 7.14$ & $0 / 0$ & $1 / 1$ & $7 / 10$ \\
$1 ; 8.16$ & $2 / 0$ & $4 / 0$ & $3 / 4$ \\
$1 ; 9.14$ & $2 / 0$ & $2 / 2$ & $5 / 11$ \\
$1 ; 10.8$ & $0 / 0$ & $0 / 6$ & $4 / 8$ \\
\hline $\begin{array}{l}\text { Frequency } \\
\text { of SER } \\
\text { (BE) }\end{array}$ & $100 \%$ & $47,05 \%$ & $35,08 \%$ \\
answers & & & \\
\hline
\end{tabular}

To calculate the frequency of occurrence of SER (BE) answers, only files where SER (BE) answers already were available are taken into account, i.e., in the case of Inês, only files beginning at 1;9.19 were taken into account. Also verbal answers involving the forms "é" (is) or "foi" (was) of the verb "ser" (to be) were not taken into account as verbal answers - these are the forms of the verb "ser" (to be) used in SER (BE) answers. To consider them as a verbal answer in this case could be misleading.

As could be noticed before, Tomás uses SER (BE) answers more extensively than Inês (even if only stage II in Inês' data is taken into account - cf. tables II and III in section 3.1). In this case, the number of occurrences of SER (BE) confirmations and other SER (BE) answers may be considered not to be sufficiently significant in at least Inês' data. However, it must be noticed that the data from the two children is coincident in two aspects:

(i) SER (BE) answers are more frequent in confirmations of declarative sentences (cf. the confirmation context in 18) than in confirmations requested through yes-no questions;

(ii) SER (BE) answers to yes-no questions that have the value of confirmation requests (cf. the confirmation context in 19) are more frequent but not significantly more frequent than SER (BE) answers to "true" yes-no questions.

Although the data presented here are not sufficiently extensive to allow for a safe conclusion, this type of results may mean that, although the child understands the specialization of SER (BE) answers as answers to confirmations (SER (BE) answers are more frequent as confirmations of declarative sentences than in other contexts), he / she is not yet completely able to deal with complex discourse contexts changing the interpretation of yes-no questions (SER (BE) answers are not as frequent in cases of answers to yes-no questions that have the value of a confirmation as in cases of 
confirmations of preceding declarative sentences). The idea would be to say that the child is (in most cases) answering to a yes-no question with the value of a confirmation as if it were a normal yes-no question.

This behavior of Inês and Tomás may also raise other questions. Remember that "true" yes-no questions differ intonationnally from yes-no questions with the value of confirmation requests - in this case prosody would be an alternative to recover the specific discourse value of the yes-no question. Some researchers have claimed that phonology, particularly prosody, could be a way to bootstrap into syntax (cf., for instance, Mazuka, 1996 or, more recently, Guasti et al., 2001 and Höhle et al., 2001). In this case, we would be thinking of a case of bootstrapping into the discourse module. The fact that Inês and Tomás do not answer to confirmation requests made through yes-no questions in the same way as they answer in other contexts of confirmation request may mean that they are not able to deal with the prosodic cue in such type of yes-no questions. Even though the children may recognize the different intonation patterns associated with the different values of the yes-no questions (an experimental setting would be needed to test this), they are not relating the different intonation patterns with different discourse values, i.e., there is no evidence at this point for prosodic bootstrapping into discourse (this of course does not mean that intonation may not be used later on in the acquisition of discourse knowledge).

There is another fact allowing to maintain the hypothesis that the ability to deal with different contexts of confirmation develops late. In European Portuguese, there is an interjection that expresses confirmation: "pois" (in fact / indeed). This interjection may precede the verb, an adverb or the forms "é" (is) or "foi" (was) in a SER (BE) confirmation; it may also appear alone, as a confirmation of a preceding declarative sentence:

(20) Speaker A: O patinho já tem um amigo. the little duck already has a friend

'The little duck already has a friend.'

Speaker B: *Pois sim. /Pois é. / Pois tem. / Pois já./ Pois. in fact yes in fact is in fact has in fact already in fact

In the case of answers to yes-no questions that are confirmation requests, the same answer pattern is observed (although in this case the SER (BE) answer is not able to recover interpretation 2 as defined for example 14 in section 2.3.2):

(21) Speaker B: O patinho já tem um amigo. the little duck already has a friend 'The little duck already has a friend.'

Speaker A: O patinho já tem um amigo? the little duck already has a friend 'Does the little duck already have a friend?' 
Speaker B: *Pois sim. /Pois é./ Pois tem./ Pois já./ Pois. in fact yes in fact is in fact has in fact already in fact

The use of "pois" by the child should then be clear evidence of the fact that the child interprets the answer he / she is giving as a confirmation. There is no occurrence of "pois" in Tomás' data $(1 ; 6.18-1 ; 10.8)$. The occurrences of "pois" (in fact) in different contexts in Inês' data are presented in Table VI.

Table VI. "pois" in answers and in confirmations in Inês' data.

\begin{tabular}{|c|c|c|c|c|}
\hline & $\begin{array}{l}\text { Use of "pois" } \\
\text { in confirma- } \\
\text { tions of pre- } \\
\text { ceding declar- } \\
\text { ative sentences }\end{array}$ & $\begin{array}{l}\text { Use of "pois" } \\
\text { in answers to } \\
\text { yes-no ques- } \\
\text { tions that are } \\
\text { confirmation } \\
\text { requests }\end{array}$ & $\begin{array}{l}\text { Use of "pois" } \\
\text { in answers to } \\
\text { yes-no ques- } \\
\text { tions that are } \\
\text { demands of } \\
\text { information }\end{array}$ & \begin{tabular}{|ll} 
Use & of \\
"pois" & in \\
answers & to \\
tags &
\end{tabular} \\
\hline $1 ; 6.6$ & 0 & 0 & 0 & 0 \\
\hline $1 ; 7.2$ & 0 & 0 & 0 & 0 \\
\hline $1 ; 8.2$ & 0 & 0 & 0 & 1 \\
\hline $1 ; 9.19$ & 0 & 0 & 0 & 0 \\
\hline $1 ; 10.29$ & 1 & 0 & 0 & 0 \\
\hline $2 ; 1.10$ & 0 & 0 & 0 & 0 \\
\hline $2 ; 2.1$ & 0 & 0 & 0 & 0 \\
\hline $2 ; 3.8$ & 0 & 0 & 0 & 0 \\
\hline $2 ; 4.19$ & 0 & 0 & 0 & 0 \\
\hline $2 ; 5.24$ & 0 & 0 & 0 & 0 \\
\hline $2 ; 7.16$ & 0 & 0 & 0 & 0 \\
\hline $2 ; 8.23$ & 0 & 0 & 0 & 0 \\
\hline $2 ; 10.20$ & 0 & 0 & 0 & 0 \\
\hline $2 ; 11.21$ & 1 & 0 & 0 & 0 \\
\hline $3 ; 0.15$ & 1 & 0 & 0 & 0 \\
\hline $3 ; 2.2$ & 0 & 0 & 0 & 0 \\
\hline $3 ; 4.6$ & 3 & 0 & 0 & 0 \\
\hline $3 ; 5.28$ & 3 & 0 & 0 & 1 \\
\hline $3 ; 7.29$ & 0 & 0 & 0 & 0 \\
\hline $3 ; 10.1$ & 3 & 0 & 0 & 1 \\
\hline $3 ; 11.12$ & 0 & 0 & 0 & 0 \\
\hline
\end{tabular}

Crucially, "pois" occurs in confirmations of preceding declarative sentences but it does not occur in answers to yes-no questions that are confirmation requests: this may in fact indicate that the child is not understanding this type of yes-no questions as if they were confirmation requests, but she is answering to those questions as if they were "true" yes-no questions. This means that the child is only taking into account syntactic information; she is not using discourse (or prosodic) information in these contexts. Interestingly, 
the other occurrences of "pois" in answers appear in answers to tags. Tags are in fact questions that are used to require confirmation, but in the case of tags the confirmation request is marked syntactically: in this case, the child uses "pois" in the answers, showing that she recognizes the context as a confirmation request. ${ }^{15}$

This data indicates that, when the child already disposes of the several patterns of answer to yes-no questions, he / she is not yet able to deal with discourse information that restrict the possible answers. At this point, he / she is also not yet able to use prosodic cues to bootstrap into discourse information.

Discussing very different phenomena, Avrutin (1999: 50) claims that "knowledge of the rules of conversation is different [from syntactic knowledge] in that its implementation relies on speakers' capacity to make inferences about other speakers representations of the conversation". The same author argues that children often fail when establishing this type of inferences. The facts presented in this section may be in agreement with this claim, even though the claim has been applied to very different processes: to understand a yes-no question as a confirmation request (without using intonation as a resource) the child has to infer that if the other speaker asks something that was already answered in the preceding discourse, he is not asking for new information but asking for a confirmation. Children seem to fail when establishing this type of inference ${ }^{16}$.

\subsubsection{Syntactic and pragmatic knowledge}

In section 2.2. it was shown that the choice of answer to a yes-no question could also involve pragmatic knowledge: SER (BE) answers are impossible as agreement answers and are impossible as answers to yes-no questions that should be interpreted as invitations or requests. Therefore, the correct choice of answer to a yes-no question in this case requires the child to correctly interpret questions that are indirect orders / demands / invitations / offers, i.e., the child has to interpret indirect speech acts correctly.

Tomás' data have several cases of (inadequate) use of SER (BE) answers as agreement answers, clearly showing that even though SER (BE) and other type of answers are syntactically available and even though the child is able to understand the question from a syntactic point of view, he is not yet able to

15 In work in preparation, I relate the increase of answers with "pois" to the emergence of tags in child's productions. In fact, in Inês' data the first occurrences of tags coincide with the emergence of "pois" - I argue that this may be related to the ability to deal with confirmation contexts.

16 Notice that this claim about late acquisition of this level of discourse knowledge does not necessarily apply to other levels of the same type of knowledge. In work in preparation, I show that early mastery of the default strategy allowing the identification of material focused in a yes-no question is directly related to the early emergence of topic / comment structures. I relate this to work on the emergence of topics developed for EP by Carrilho (1994) and for French by De Cat (2002). 
deal with this type of pragmatic restriction. The following are examples of these non-adult answers:

(22) *MAE: olha \# filho \# olha aqui .

look son look here

'Son, look, look over here.'

*MAE: vamos ver este \# agora?

are (we) going to see this now

'Shall we have a look at this one now?'

*TOM: é .

is

[Tomás $1 ; 7.14]$

(23) *MAE: +, mas não és capaz ?

but not are able

'But aren't you capable?'

*TOM: $\mathrm{xxx}$.

*MAE: ajudo ?

help $\left[1^{\text {st }} \mathrm{sg}\right]$

*TOM: é

'Do you want me to help you?'

is

[Tomás 1;9.14]

The absolute number of occurrences in Tomás' data are the following: three occurrences at 1;7.14; two occurrences at 1;8.16; one occurrence at 1;9.14. The fact that these non-adult answers are not found in Inês' data may be simply due to the fact that Inês does not use SER (BE) answers as extensively as Tomás. But Inês' data presents other type of evidence that allow us to say that recognition of answers to yes-no questions as agreement contexts may come late. In European Portuguese, we can express agreement in these contexts by answering "tá" (meaning o.k.). In acquisition data, this type of answer to yes-no questions would mean that the child clearly identifies relevant contexts as indirect speech acts. TÁ (o.k.) answers do not occur in Tomás files $(1 ; 6.18-1 ; 10.8)$ and they only occur late (but in adequate contexts) in Inês' data: once at $3 ; 0.15$ and once at $3 ; 10.1$.

It is also interesting to verify that a phatic use of "sim" (yes), which is possible during conversational interaction and completely dependent of the identification of an adequate pragmatic context, is rare or not found in the corpus. In Tomás' data, there are no occurrences of this type of "sim". In Inês' data, it occurs once, at $3 ; 11.12$, i.e., at a late stage in the process of acquisition and much later than the emergence of "sim" in other contexts. 
(24) *MAE: olha \# nês@f +...

look (I)nês

'Inês, look.'

*INI: $\operatorname{sim}$

yes

*MAE: +, nês@f \# queres fazer o quê \# agora ?

(I)nês want $\left[2^{\text {nd }} \mathrm{sg}\right]$ to do what now

'Inês, what do you want to do now?' [Inês 3;11.12]

The data presented in this section once again prove the autonomy of the syntactic module: even if the child is already able to produce the different types of answer to yes-no question, he / she may not be able to deal with pragmatic factors which restrict the answering possibilities. This should be taken as evidence for the claim that syntactic and pragmatic modules are autonomous modules.

\section{Summary:}

The data discussed in this section showed that the emergence of the several answer patterns is not coincident with the acquisition of certain types of knowledge at the level of discourse or pragmatics that interfere with the choice of answer. There is clear evidence that even when the child is able to produce the different types of answers to yes-no questions he / she is still not completely able to deal with discourse or pragmatic information that restrict the choice of answer. In this case, the acquisition of yes-no questions may provide evidence for the claim that the acquisition of syntactic, discourse and pragmatic knowledge are independent processes, since they refer to autonomous modules.

3.3. The acquisition of minimal answers and the identification of the material focused in the question

So far it was shown that children that acquired the different patterns of answers to yes-no questions may not use these patterns in an adultlike way, since they have not yet stabilized the elements of discourse and pragmatic knowledge that are needed to behave appropriately in these contexts. This leads to a distinction between the process of acquisition of syntax and the processes of acquiring discourse and pragmatic knowledge.

However, data from the acquisition of answers to yes-no questions also provide evidence for modularity in acquisition within the computational system: it can be shown that children having acquired functional categories involved in answers to yes-no questions may be unable to deal in an adultlike way with syntactic and semantic factors that force an interpretation of the question that is deviant of the default case.

Remember that there are some syntactic restrictions to the choice of answer to a yes-no question and that these restrictions involve scope relations. In 
section 2.1., it was claimed that verbal answers are only possible when the material focused in the question is defined by default. We consider the verb in the question and all the material it c-commands default focused material. When syntactic (identificational focus, for instance) or some specific discourse factors intervene, the material focused in the question may be defined by higher categories - in these cases, a verbal answer is unavailable.

In the corpus we can find cases where the child gives verbal answers when the identification of the material focused in the question would not allow such an answer - crucially, at the moment the child gives such answers, he / she already produced SIM (yes) or SER (BE) answers, which would be perfect answers to these questions. This is the case of answers to yes-no questions involving identificational focus structures (clefts or structures with the adverb "só" (only) - Kiss, 1998) - the following are all non-adult answers in European Portuguese:

$\begin{array}{lllll}\text { (25) MAE: } & \text { só } & \text { queres } & \text { o } & \text { vermelho ? } \\ & \text { only } & \text { want }\left[2^{\text {nd }} \mathrm{sg}\right] & \text { the } & \text { red one }\end{array}$ 'Do you only want the red one?'

INI: $\quad \mathrm{s}[/ /]$ \# quero \# e(s)te . want this one [Inês $2 ; 8.23]$

(26) ALS: olha \# é o ursinho \# que dá a luz ? look is the little bear who sheds the light 'Look, is it the little bear who sheds the light?'

TOM: dá . sheds

[Tomás 1;9.14]

(27) MAE: olha \# quem bate ao Tás@f? look who beats to+the Tás 'Look, who beats Tás?'

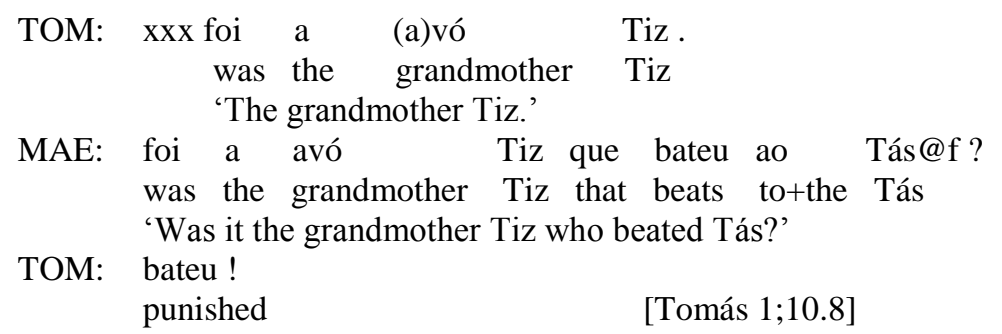

In (25), the child gave a verbal answer to a question whose interpretation has been changed by the adverb "só" (only) placed in preverbal position (cf. sections 2.1. and 2.4.). In the case of (26) and (27), subjects are clefted in the questions, blocking a default interpretation of the question. In these cases, and according to what has been said in section 2.1., it is not possible to answer 
with the lower verb in the question. The only possible verbal answer is the one that chooses the verb in the cleft. However, the child answered with the lower verb in (26) and (27). This happens for one of two reasons (or for both reasons): either the child is not yet sensitive to changes in the interpretation of questions that are induced by clefts or focalization adverbs or he / she is not conscious of the fact that in EP an answer to a yes-no question recovers the material focused in the question. In the latter case, it is possible that the child is producing verbal and SIM (yes) or SER (BE) answers as being equivalent in their interpretation.

In fact, all the cases where there is more than one verb in the question could be a potential problem in order to determine what could be the possible verbal answer. So far, we have claimed that the material focused in a yes-no question is identified with the verb and everything it c-commands, in absence of other intervening factors. Notice that in those cases where more than one verb occurs in the question, it should be determined which of the verb is relevant for defining the material focused in the question. In fact, it seems that what we can identify as the scope of a yes-no question must be able to have the status of an assertion. This is illustrated by the behavior of question-answer pairs involving assertive predicates such as "achar" (to think) (cf. 28) and pseudo-assertive predicates such as "querer" (to want) (cf. 29).

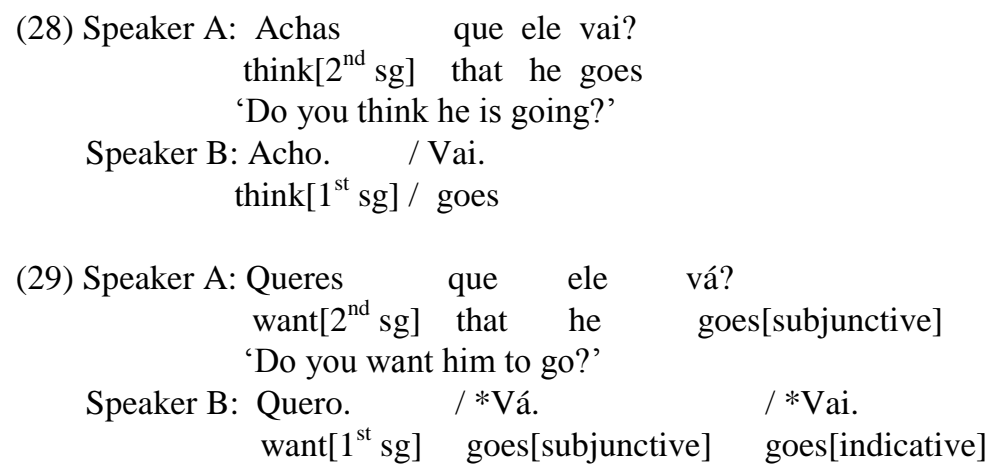

In the case of the assertive predicate (cf. 28), the material focused in the question may be identified with the c-command domain of the higher verb as well as with the c-command domain of the embedded verb. In this case, verbal answers that recover the higher or the lower verb are both possible, although an adult would feel the c-command domain of the higher verb as the most natural choice. In the case of the pseudo-assertive predicate (cf. 29), only the c-command domain of the higher verb may be identified as the material focused in the question. Crucially, the embedded clause selected by a pseudo-assertive predicate may not be identified with an assertion.

Bosque (1990) presents several tests allowing to distinguish assertive and pseudo-assertive predicates. Interestingly, one of them deals with the possi- 
bility of ellipsis recovering the sentential complement of the verb. According to this test, only complements of assertive predicates, i.e., only complement clauses that count as assertions may be recovered under ellipsis. Complement clauses that count as assertions are also the type of complement clauses which may be identified as the material focused in a yes-no question and, consequently, may be recovered by a verbal answer using the verb in the complement clause.

Tables VII and VIII present the behavior of Inês and Tomás when answering to questions that involve sentential complements. The columns present the type of answers the child gives when it is possible to answer with both the higher and the lower verb and the type of answers he / she gives when only the verbal answer involving the higher verb is available. ${ }^{17}$

Data from Inês and Tomás show that contexts where the scope of the question is not ambiguous (cf. cases where only the verbal answer involving the higher verb is possible) are not a problem for the child: he / she correctly answers with the higher verb. However, in contexts where both the c-command domain of the higher verb and the c-command domain of the lower verb may be identified as defining the material focused in the question, the child seems to prefer the narrower scope (cf. $70 \%$ of answers involving the lower verb in Inês' data). In fact, this is not the adult preference. In these cases, and in absence of a situational context, adult speakers prefer to attribute the broader scope to the question and, consequently, to answer with the higher verb.

17 Besides the assertive / non-assertive status of the predicate, other factors intervene to determine whether it is possible to answer with the lower verb. For instance, it seems that when an assertive predicate selects a non-finite complement, it is not possible to answer with the embedded verb. A non-finite complement may not count as an assertion. 
Table VII. Verbal answers / confirmations of questions / declarative sentences presenting embedding in Inês' data.

\begin{tabular}{|c|c|c|}
\hline & $\begin{array}{l}\text { It is possible to answer both } \\
\text { with the higher and the lower } \\
\text { verb }\end{array}$ & $\begin{array}{l}\text { Only the answer } \\
\text { involving the higher } \\
\text { verb is available }\end{array}$ \\
\hline & $\begin{array}{l}\text { Number of answers using the } \\
\text { embedded verb / number of } \\
\text { answers using the verb in the } \\
\text { main clause }\end{array}$ & $\begin{array}{l}\text { Number of answers } \\
\text { using the embedded } \\
\text { verb / number of } \\
\text { answers using the verb } \\
\text { in the main clause }\end{array}$ \\
\hline $1 ; 6.6$ & $0 / 0$ & $0 / 0$ \\
\hline $1 ; 7.2$ & $0 / 0$ & $0 / 0$ \\
\hline $1 ; 8.2$ & $0 / 1$ & $0 / 0$ \\
\hline $1 ; 9.19$ & $0 / 0$ & $0 / 1$ \\
\hline $1 ; 10.29$ & $1 / 0$ & $0 / 4$ \\
\hline $2 ; 1.10$ & $0 / 0$ & $0 / 2$ \\
\hline $2 ; 2.1$ & $1 / 0$ & $0 / 4$ \\
\hline $2 ; 3.8$ & $1 / 0$ & $0 / 1$ \\
\hline $2 ; 4.19$ & $0 / 0$ & $0 / 3$ \\
\hline $2 ; 5.24$ & $0 / 1$ & $0 / 1$ \\
\hline $2 ; 7.16$ & $1 / 0$ & $0 / 1$ \\
\hline $2 ; 8.23$ & $0 / 0$ & $0 / 0$ \\
\hline $2 ; 10.20$ & $2 / 0$ & $0 / 0$ \\
\hline $2 ; 11.21$ & $0 / 0$ & $0 / 0$ \\
\hline $3 ; 0.15$ & $0 / 0$ & $0 / 0$ \\
\hline $3 ; 2.2$ & $1 / 0$ & $0 / 0$ \\
\hline $3 ; 4.6$ & $0 / 1$ & $0 / 0$ \\
\hline $3 ; 5.28$ & $0 / 0$ & $0 / 1$ \\
\hline $3 ; 7.29$ & $0 / 0$ & $0 / 0$ \\
\hline $3 ; 10.1$ & $0 / 0$ & $0 / 0$ \\
\hline $3 ; 11.12$ & $0 / 0$ & $0 / 0$ \\
\hline Frequency & $70 \% / 30 \%$ & $0 / 100 \%$ \\
\hline
\end{tabular}


Table VIII. Verbal answers / confirmations of questions / declarative sentences presenting embedding in Tomás' data.

\begin{tabular}{|c|c|c|}
\hline & $\begin{array}{l}\text { It is possible to reply both } \\
\text { with the higher and the lower } \\
\text { verb } \\
\text { Number of answers using the } \\
\text { embedded verb / number of } \\
\text { answers using the verb in the } \\
\text { main clause }\end{array}$ & $\begin{array}{l}\text { Only the reply involving } \\
\text { the higher verb is } \\
\text { available } \\
\text { Number of answers } \\
\text { using the embedded } \\
\text { verb / number of } \\
\text { answers using the verb } \\
\text { in the main clause }\end{array}$ \\
\hline $1 ; 6.18$ & $0 / 0$ & $0 / 1$ \\
\hline $1 ; 7.14$ & $0 / 0$ & $0 / 0$ \\
\hline $1 ; 8.16$ & $0 / 0$ & $0 / 0$ \\
\hline $1 ; 9.14$ & $0 / 0$ & $0 / 1$ \\
\hline $1 ; 10.8$ & $0 / 0$ & $0 / 2$ \\
\hline Frequency & - & $0 / 100 \%$ \\
\hline
\end{tabular}

In (30) and (31), Inês' answers in these cases are contrasted with the typical adult answer.

$$
\begin{aligned}
& \text { (30) *MJF: achas que ela já esta a dormir? } \\
& \text { think } \mathrm{k}_{[2 \mathrm{ndsg}]} \text { that she already is } \\
& \text { 'Do you think that she is already sleeping?' }
\end{aligned}
$$

*INI: (es)tá .

is

[Inês 2;2.1]

Adult answer: Acho.

think

(31) *MAE:tu tens a certeza de que no céu há flores ? you are sure that in+the sky there are flowers 'Are you sure that there are flowers in the sky?'

*INI: há

there are

[Inês 2;3.8]

Adult answer: Tenho.

am

The fact that these non typically adult answers occur after the emergence of SIM (yes) and SER (BE) answers (which would be appropriate answers in these contexts) must mean that the identification of the material focused in the question is the problem the child is dealing with. The child seems to know that the material focused in a question must qualify as an assertion. However, in 
cases where the identification of the focus of the question is ambiguous, the child typically picks the non-adult option: he / she chooses the narrower scope. This means that the emergence of the functional categories hosting "sim" (yes) or SER (BE) in answers does not happen at the same time as the complete identification of the material focused in yes-no questions.

In fact, the difficulty to deal with a non default interpretation of a question may be the cause of the delay in the acquisition of answers involving "só" (only). In Inês' data, there are three productive types of adverbial answers: answers involving "só" (only), answers involving "também" (also) and answers involving "já" (already). In fact, these three types are not acquired at the same time, which perfectly matches the idea that adverbial answers are not structurally homogeneous (cf. section 2.4): in Inês' data, "já" (already) answers occur at 1;9.19, "também" (also) answers occur at 2;5.24 and "só" (only) answers only occur at 3;7.29. In Tomás' data $(1 ; 6.18-1 ; 10.8)$, there are only two occurrences of adverbial answers, both with the adverb "já" (already) $)^{18}$. This means that "só" (only) is apparently the latest adverb emerging in answers to yes-no questions. "Só" (only) is an adverb involved in identificational focus structures and consequently able to change the definition of what is focused in yes-no questions. In fact, an answer using "só" (only) is a complete evidence of exact identification of the material focused in a question - the fact that this type of answer emerges late must mean that the ability to identify the material focused in a question also comes late.

\section{Summary:}

In this section, it was shown that a child may have only partially acquired the relevant syntactic and semantic knowledge involved in answers to yes-no questions. Children who already have acquired the different functional categories involved in answers to yes-no questions (they already have available SIM (yes) or SER (BE) answers, which seem to involve the presence of high left peripheral positions) may not yet be able to deal in an adultlike way with the definition of the focused material in questions. In these cases, children seem to (i) define the focus of a question by default in cases where this is not possible and (ii) prefer the narrower interpretation in questions where embedding of subordinate clauses causes ambiguity.

\section{Conclusion}

The data presented in this paper allow us to say that (i) the process of acquisition of answers to yes-no questions provides additional evidence for the claim that not all patterns of answer are structurally equivalent and (ii)

${ }^{18}$ In this paper, I am not assuming any particular analysis of these adverbs. In other words, I am not linking the different adverbs to particular functional projections. I leave this for future reseach. 
answers involving lower functional categories are acquired earlier than answers involving high left peripheral positions. It also provides evidence for modularity of syntactic, discourse and pragmatic knowledge. Finally, it provides evidence for modularity within the computational module (a child may have acquired the functional categories involved in different patterns of answers to yes-no questions without being able to deal with the identification of the focused material in a yes-no question, which restricts the choice of an answer pattern).

\section{Acknowledgements}

I thank Inês Duarte and Nina Hyams for discussion of this paper and previous work. I am also sincerely indebted to the two anonymous reviewers who discussed and contributed to improve this paper. Finally, thanks to Tjerk Hajemeijer, who is always available for last minute reviews.

\section{References}

Avrutin, S. (1999) Development of the syntax-discourse interface. Dordrecht / Boston / London: Kluwer Academic Publishers.

Bosque, I. (1990) Las bases materiales de la alternancia modal. Repaso y balance. In Indicativo y subjuntivo (I. Bosque, editor), pp. 13-65. Madrid: Taurus Editora.

Brito, A. M. (2001) Clause Structure, subject positions and verb movement - about the position of Sempre in European and Brazilian Portuguese. In Romance languages and linguistic theory 1999. (Y. d'Hulst, J. Rooryck \& J. Schroten, editors), pp. $63-$ -85. Amsterdam / Philadelphia: John Benjamins Publishing Company.

Carrilho, E. (1994) A topicalização e a construção de objecto nulo no desenvolvimento sintáctico do Português Europeu (a produção espontânea de duas crianças dos 2;00 aos 3;03 anos). Master Dissertation. Lisboa: Faculdade de Letras da Universidade de Lisboa.

Costa, J. (1996) Adverb positioning and V-movement in English: some more evidence. Studia Linguistica $\mathbf{5 0 .}$

Cyrino, S. \& G. Matos (2002) VP ellipsis in European and Brazilian Portuguese - a comparative analysis. Journal of Portuguese Linguistics 1 (2), 177-195.

De Cat, C. (2002) French dislocation. PhD Dissertation. University of York.

Freitas M. J. (1997) Aquisição da estrutura silábica do Português Europeu. PhD Dissertation. Lisboa: Universidade de Lisboa.

Gonzaga, M. (1997) Aspectos da sintaxe do advérbio em Português. Master Dissertation. Lisboa: Faculdade de Letras da Universidade de Lisboa.

Guasti, T. et al. (2001) Pre-lexical setting of the head: complement parameter through prosody. In Approaches to Bootstrapping. Phonological, Lexical, Syntactic and Neurophysiological Aspects of Early Language Acquisition (J. Weissenborn \& B. Höhle, editors), pp. 231-248. Amsterdam / Philadelphia: John Benjamins Publishing Company. 
Höhle, B. et al. (2001) Discovering word order regularities: the role of prosodic information for early parameter setting. In Approaches to bootstrapping. Phonological, lexical, syntactic and neurophysiological aspects of early language acquisition (J. Weissenborn \& B. Höhle, editors), pp. 249-265. Amsterdam / Philadelphia: John Benjamins Publishing Company.

Kiss, K. É. (1998) Identificational Focus versus Information Focus. Language. Journal of the Linguistic Society of America, 74 (2), 245-273.

Laka, I. (1990) Negation in syntax. On the nature of functional categories and projections. Cambridge: MIT Working Papers in Linguistics.

MacWhinney, B. \& C. Snow (1985) The child language exchange system. Journal of Child Language 12, 271-296.

Martins, A. M. (1994) Os Clíticos na História do Português. PhD Dissertation. Lisboa: Universidade de Lisboa.

Mata, A. I. (1990) Questões de entoação e interrogação em Português. "Isso é uma pergunta?". Master Dissertation. Lisboa: Faculdade de Letras da Universidade de Lisboa.

Matos, G. (1992) Construções de elipse do predicado em Português. SV nulo e despojamento. PhD Dissertation. Lisboa: Universidade de Lisboa.

Mazuka, R. (1996) Can a grammatical parameter be set before the first word? Prosodic contributions to early setting of a grammatical parameter. In Signal to syntax (J. L. Morgan \& K. Demuth, editors), pp. 313-330. Mahwah, N.J.: Lawrence Erlbaum.

Santos, A. L. (2002a) Answers to yes-no questions and clitic placement: the question of adverbs. Actas do XVII Encontro Nacional da Associação Portuguesa de Linguística. Lisboa: APL.

Santos, A. L. (2002b) Aquisição de padrões de resposta a interrogativas globais em Português Europeu. Talk given at XVIII Encontro Nacional da Associação Portuguesa de Linguística. Porto.

Searle, J. R. (1975) A taxonomy of illocutionary acts. In Language, mind and knowledge (K. Gunderson, editor), pp. 344-369. Minneapolis: University of Minnesota Press.

\author{
Ana Lúcia Santos \\ Universidade de Lisboa \\ Portugal \\ als@ip.pt
}

